\title{
Comunidade epistêmica e a formação da reforma sanitária no Brasil
}

\section{| ${ }^{1}$ Nilson do Rosário Costa |}

Resumo: $\mathrm{O}$ artigo trata da análise politica que sustentou a Reforma Sanitária Brasileira (RSB), responsável pela definição do Sistema Único de Saúde e pela ideia do direito universal contemplada pela Constituição Federal de 1988 (CF 1988). O texto ilumina a singular contribuição da comunidade de epistêmica dos sanitaristas para a formação da agenda de política pública redistributiva da saúde no contexto da redemocratização. $\mathrm{O}$ artigo revisa também as explicaçôes para a fragmentação e influência do setor privado do sistema de saúde brasileiro, a despeito do sucesso institucional da proposta da universalização redistributiva. Destaca que a RSB não contemplava o veto à presença do mercado no setor saúde, o que reduziu os custos políticos para o setor privado impusesse suas preferências na Nova Democracia. O artigo conclui que a análise dos limites estruturais e institucionais para uma política pública redistributiva na saúde é ainda um desafio para a comunidade de especialistas da saúde coletiva.

Palavras-chave: Reforma Sanitária; comunidade epistêmica; democratização; universalismo; privatização.
1 Departamento de Ciências Sociais, Escola Nacional de Saúde Pública da Fiocruz. Rio de Janeiro-RJ, Brasil. Endereço eletrônico: nilsondorosario@ terra.com.br Aprovado em: 15/07/2014 
Este artigo descreve as raízes sociais e intelectuais e o contexto institucional que viabilizou a proposta da reforma sanitária (RS) brasileira. A RS foi responsável pela definição do Sistema Único de Saúde (SUS) e pela proposta da universalização da assistência à saúde na Constituição Federal de 1988 (CF1988).

A comunidade epistêmica que produziu a análise política da reforma do setor saúde tem sido denominada como "sanitaristas" (WEYLAND, 1996; ARRETCHE, 2010). Nas ciências sociais, a comunidade epistêmica é definida como o conjunto de indivíduos disseminado nas agências de governo, nos departamentos e institutos de pesquisa, partidos políticos, organizações não governamentais e grupos de interesse que atua numa área específica de política pública (HAAS, 1996). Pode-se afirmar que os sanitaristas apresentavam as características de comunidade política assinaladas pela literatura em razão da atuação específica - legitimada pela autoridade científica - no debate nacional sobre a reorganização do sistema de saúde.

Sob o ponto de vista do status científico, seu traço mais relevante era a condição funcional de docentes e pesquisadores de agências e universidades públicas. Na década de 1980, a inserção dos sanitaristas nessa estrutura estatal era muito especial: detinham as condições de burocracia organizacional weberiana (especialmente a estabilidade funcional) combinadas com autonomia decisória típica das burocracias acadêmicas. $\mathrm{O}$ insulamento profissional foi retroalimentado pela expressiva participação dos médicos da esfera acadêmica na condução da RS. A influência da condição social e profissional dos sanitaristas foi, nesse sentido, crucial para o alcance da RS.

Ao analisar o sistema de saúde brasileiro, os sanitaristas apresentaram como particularidade a atuação em uma área especializada, visão de mundo e independência de uma burocracia pública profissional. A análise política dos sanitaristas, que levou à adoção do projeto universalista de direito à saúde no âmbito da transição democrática da década de 1980, foi realizada a partir do aparelho de Estado e não da mobilização da sociedade civil ou do movimento social. O papel na análise política da burocracia pública especializada não é desconhecido pela literatura internacional (DOBUZINSKIS et al., 2007).

Cabe destacar também que a influência dos sanitaristas foi centralmente conquistada pela análise política oportuna, pontual e propositiva. Não obstante, o sucesso na formação e implantação de uma agenda de política não teve como 
base a difusão maciça de "evidências científicas" longamente consolidadas que legitimaram a proposta de reforma do sistema de saúde. As abordagens sobre o papel das comunidades epistêmicas ou de especialistas enfatizam o uso da autoridade científica para superar as dúvidas sobre a adequação ou plausibilidade da implantação de políticas públicas. O recurso à evidência científica impõe-se geralmente nas situações onde o que é falso ou verdadeiro não é completamente percebido pelos tomadores de decisão (HAAS, 1996). Majone chama atenção, entretanto, para o fato de que apenas a evidência científica não é suficiente para a legitimação das opções oferecidas pela análise política. Os especialistas têm que convencer os atores sociais nas diversas arenas em que se propõem a atuar. Nessa situação, os argumentos seriam mais eficazes que as evidências científicas (MAJONE, 1989).

De acordo com o que sugere Hall (1989), cabe responder sobre as circunstâncias que permitem a difusão de ideias inovadoras. Nessa perspectiva, este artigo mostra que a RS foi resultado da organização de novos sujeitos políticos que, aproveitando uma conjuntura favorável de democratização no Brasil dos anos 1980, definiram o SUS como objetivo institucional por meio de argumentos.

Por que os argumentos foram acolhidos? O projeto do SUS foi aceito pelas elites políticas nacionais numa conjuntura de crise de um regime autoritário (1964-1984) e de transição democrática (1985-1990). O processo institucional brasileiro que possibilitou a eficaz atuação dos sanitaristas tinha três traços fundamentais. Primeiro, não havia poder de veto à agenda de política setorial de atores sociais relevantes, como o setor sindical corporativo que controlara a previdência social e o acesso à assistência médica individual ao longo da história republicana. Ao longo do regime autoritário, os sindicatos haviam sofrido perdas específicas e concentradas que alijaram os representantes dos trabalhadores do processo decisório na previdência social e, consequentemente, sobre organização da assistência médica. Malloy mostra que o regime militar autoritário de 1964 moveu-se com dedicação para controlar o movimento trabalhista (MALLOY, 1979).

Segundo, a falência da centralização decisória do regime autoritário trouxe automaticamente para a arena política a voz de lideranças do Legislativo, Judiciário, instâncias federativas então secundárias - estados e municípios - e coalizões de especialistas setoriais. Sob a perspectiva da federação, a 
centralização autoritária desapropriou os estados e os municípios da intervenção social em três sentidos: ao concentrar recursos financeiros no Executivo federal; ao estabelecer normas gerais aplicáveis às políticas sociais e ao submeter as aplicações dos fundos federais à decisão da União, evitando sempre os repasses automáticos de recursos (DRAIBE, 1989).

Terceiro, os argumentos dos sanitaristas na CF1988 receberam o reforço favorável da elite política democratizante que defendia o resgate da "dívida social" brasileira. Na época, por exemplo, Jaguaribe e outras lideranças intelectuais afirmavam que não seria possível uma democracia estável no Brasil enquanto não fosse "significativamente reduzido o abissal fosso aberto entre as grandes massas e os estratos superiores da população" (JAGUARIBE et al., 1986, p. 15).

No contexto da transição democrática, o escopo das escolhas institucionais foi muito ampliado, suspendendo temporariamente os constrangimentos estruturais para as mudanças nas políticas públicas. Os grupos de interesse encontraram condições de exercer influência na gestação das novas políticas. A ação coletiva assumiu uma configuração pluralista, como descrita por Granados e Knoke (2005), em função da forte competição entre os grupos de interesse emergentes e a fragmentação do poder. A transferência da coordenação política para o processo constituinte (1987-1988) reduziu o papel do governo autoritário na intermediação de interesses.

$\mathrm{Na}$ teoria paradigmática da formação da agenda pública, a janela política é o momento em que os defensores de propostas singulares "empurram" as soluções para problemas. Os empreendedores atuam decisivamente no acoplamento, na janela política, das soluções aos problemas, superando os constrangimentos pela adaptação das propostas às circunstâncias (KINGDON, 2003). O período da transição democrática no Brasil apresentou, nesse sentido, uma oportunidade para novas escolhas institucionais na política pública de saúde em razão da fragmentação da arena setorial e do frágil poder de veto de grupos de interesses relevantes, especialmente os sindicatos, como já mencionado, ou mesmo as empresas e organizaçóes da saúde beneficiadas pelo regime militar. Diante desse quadro, o setor saúde pôde ser tomado por novíssimos formuladores de políticas públicas cuja autoridade científica de campo científico recém emergia no país (NUNES, 1994). 


\section{Autoritarismo, nacional desenvolvimentismo e política de saúde}

$\mathrm{O}$ autoritarismo brasileiro não foi completamente nulo no enfrentamento da questão social durante toda sua existência. A tentativa de intervenção redistributiva foi especialmente buscada na segunda metade dos anos 1970. Essa intervenção respondeu à crítica à falência da política social do regime, especialmente na saúde. A expressão maior da falência da política social era exemplificada pelo aumento da mortalidade infantil na cidade de São Paulo em fins da década de 1960, no ápice do ciclo do crescimento contínuo do produto interno bruto propagandeado como "milagre econômico brasileiro", e o efeito devastador da epidemia de meningite de 1974 (MALLOY, 1979).

O governo Geisel (1974-1979) produziu uma resposta específica à percepção coletiva da crise social do país. O ativismo social do regime militar durante esse governo autocrático levou à criação do Ministério da Previdência e Assistência Social (MPAS) em 1974. Santos identifica, após a criação do MPAS, o reforço substantivo da proteção social (SANTOS, 1979). Noronha e Levcovitz assinalam, no Plano de Pronta Ação (PPA), a iniciativa includente na assistência à saúde que produziu, após 1974, um "aumento sem precedentes na produção de serviços" (NORONHA; LEVCOVITZ, 1994, p. 78).

Em 1977, a complexificação do sistema de seguro social levou à criação do Sistema Nacional de Previdência e Assistência Social (SINPAS), composto pelo Instituto de Administração Financeira (IAPS), Instituto Nacional de Previdência Social (INPS) e Instituto Nacional de Assistência Médica (INAMPS). Ao INAMPS coube a responsabilidade pela prestação de assistência médica individual aos trabalhadores urbanos, servidores do estado, aos trabalhadores e empregados rurais (BRAGA; PAULA, 1981).

A universalização da previdência social impunha a abertura do acesso aos serviços de saúde - hospitais e ambulatórios - para um contingente de população inesperado. Malloy mostra que a previdência social brasileira abrangia $80 \%$ da população urbana brasileira (MALLOY, 1979). O acesso aos serviços de saúde previdenciários não mais era interditado aos trabalhadores autônomos, empregadas domésticas e população rural. A tentativa de conversão maciça à cidadania social demandou, consequentemente, o investimento na oferta de 
novos serviços médicos. A escolha do regime autoritário foi a articulação entre a esfera pública e privada para a ampliação da provisão previdenciária (BRAGA; PAULA, 1981). Contudo, a baixa legitimidade do regime militar não permitiu que o Executivo ganhasse reconhecimento ou tivesse capacidade de condução intelectual das iniciativas setoriais. Cabe, entretanto, destacar que os termos do debate sobre a política social na segunda metade da década de 1970 não mais se limitavam ao problema da inclusão social (SANTOS, 1979). A reflexão na política social contemplava novos questionamentos: o excesso de gastos e a ineficiência da alocação dos recursos públicos. Weyland compreende com argúcia complexidade do novo cenário:

[...] a health professionals and experts from academia and research institutes criticized this unequal and wasteful model of health care ever more vocally. In the mid of 1970 s, they formed a "sanitary movement" demanding profound reform. This social movement attributed the problems of the established system to its heavy reliance on the private sector. It therefore called for strengthening the public sector in order to guarantee all citizens equal rights and effective access to health care and to shift the emphasis from curative treatments to preventive measures, such as vaccination and sanitation. (...) It would also limit the explosion of health spending by diminishing the need for the expensive treatment of people falling ill with diseases that are easy to prevent [...] (WEYLAND, 1996, p. 15).

O autor destaca o criticismo da produção intelectual inicial dos sanitaristas em relação à opção nacional-desenvolvimentista do militares brasileiros de favorecer as empresas privadas para expandir a oferta de hospitais e ambulatórios especializados por meio das compras governamentais da Previdência Social. A análise política no campo da saúde dialogava, assim, com as decisões que alargaram a estrutura da proteção social brasileira nos anos 1970, mas não as reconhecia como legítimas ou mesmo necessárias.

A crise de legitimidade do modelo de expansão do setor saúde punha em xeque o tardio sistema de proteção social esboçado pelo regime autoritário, modelado na parceria entre Estado e empresa privada prestadora de serviços de saúde à Previdência Social. Noronha e Levcovitz (1994) registram que mesmo no âmbito da própria burocracia previdenciária havia discordância em relação ao modelo.

\section{A análise política dos sanitaristas}

Os fundamentos intelectuais da reforma sanitária tiveram como principal fonte os resultados dos estudos demandados pela Financiadora de Estudos e Projetos (FINEP), organização do Executivo Federal sediada na cidade do Rio de Janeiro, 
executora de parte programa de modernização da pesquisa científica e tecnológica governo Geisel (COSTA, 1992).

A despeito da vinculação burocrática ao aparelho de Estado de um regime autoritário, a produção científica dos sanitaristas concentrou-se, paradoxalmente, na desconstrução da política de assistência médica do governo. Para os sanitaristas, antes de instrumento de expansão da proteção social, a ampliação da assistência à saúde promovida pelo regime subordinaria de maneira inaceitável o setor Saúde à lógica do desenvolvimento capitalista. Oliveira e Teixeira exemplificam a perspectiva estrutural-funcional que fundamentava o veto à articulação entre a esfera estatal e o mercado na saúde naquele contexto. Para os autores, a expansão da previdência social na saúde era parte do processo da acumulação, facilitado pela especial articulação entre o Estado e o capital monopolista no Brasil.

Eles identificaram três características singulares da articulação entre a política social e a acumulação. A primeira seria a extensão da cobertura previdenciária de forma a abranger a quase totalidade da população urbana e ainda parte da população rural; a segunda, o privilegiamento da prática médica curativa, individual, assistencialista e especializada em detrimento de medidas de saúde pública, de caráter preventivo e de interesse coletivo; e terceira, a criação de um complexo médico-industrial, responsável pelas elevadas taxas de acumulação do capital das grandes empresas monopolistas internacionais na área de produção de medicamentos e equipamentos médicos (OLIVEIRA; TEIXEIRA, 1985).

No mesmo contexto institucional, a análise política de Cordeiro do início dos anos 1980 destacou o processo de capitalização da prática médica que articularia o conjunto de instituições prestadoras de assistência à saúde, de formação de recursos humanos e de produção de insumos, materiais (medicamentos e equipamentos) à constituição do complexo médico-industrial (CORDEIRO, 1980). O autor afirma que:

[...] a privatização da medicina, processo que se acelera a partir de 1976, encontrara suas bases materiais no setor privado hospitalar lucrativo e não lucrativo [...] a opção política encontrou como justificativa racional a existência de um setor hospitalar privado [...] aliada à expansão da demanda gerada pela incorporação de grandes contingentes de assalariados urbanos ao sistema previdenciário. (CORDEIRO, 1980, p. 162).

A pesquisa científica detinha paradoxal autonomia intelectual para reiterar a perspectiva teórica estrutural-funcional que vinculava a expansão da provisão 
do Estado na área da saúde à acumulação. A pesquisa científica dos sanitaristas reiterava as representações estruturalistas da relação entre a economia e a política, dominantes nas ciências sociais brasileiras na época. Por exemplo, em 1973, Donnangelo, referência intelectual central para a pesquisa em ciências sociais na saúde nos anos 1970, afirmava:

[...] podem ser assim explicitadas as principais condições através das quais a modalidade de interferência estatal tem preservado o setor privado: ao sustentar, pela manipulação concentrada de recursos, uma procura ampliada quantitativa e qualitativamente; ao garantir a continuidade e expansão, sob o controle privado, de uma rede de serviços que incorpora progressivamente a tecnologia moderna; ao manter o produtor privado no controle direto dos processos de produção. (DONNANGELO, 1973, p. 37).

A autora alertava, entretanto, que os limites desse privilegiamento do produtor privado estavam contidos na necessidade de conciliá-lo com a garantia de acesso aos assalariados ao consumo de serviços. Ainda assim, o privilegiamento tornava as decisões políticas menos permeáveis à racionalização e concentrava no Estado as pressões para a ampliação da esfera de atuação privada (DONNANGELO, 1973).

$\mathrm{O}$ que é especialmente instigante na experiência dos sanitaristas é que o processo Constituinte exigiu argumentos institucionais que justificassem o projeto de reforma setorial. Esses argumentos efetivamente foram produzidos, porém o imperativo da agenda institucional distanciou a análise política dos sanitaristas das representações anticapitalistas de sua produção intelectual inicial.

A difusão da análise política dos sanitaristas na Constituinte foi nacionalizada por meio de duas entidades que aglutinaram, nos anos 1970, os docentes e pesquisadores dos Departamentos de Medicina Social ou Preventiva das Faculdades Públicas Estaduais e Federais de Medicina e da Escola Nacional de Saúde Pública da Fundação Oswaldo Cruz: o Centro Brasileiro de Estudos de Saúde (CEBES) e a Associação Brasileira de Pós-Graduação em Saúde Coletiva (ABRASCO). A condição social de burocracia pública, mesmo que intelectualmente independente, exigiu dos sanitaristas a criação das duas entidades civis para a difusão da agenda reformista. Na década de 1970, o regime autoritário ainda detinha poder de limitar o ativismo político direto das organizações públicas.

O CEBES foi criado em 1976 em torno da Revista Saúde em Debate. Como registra Cohn, a entidade reuniu os acadêmicos e os profissionais de saúde do setor público que elegeram como eixo da análise política a reforma do sistema 
de saúde na perspectiva da universalização e equidade sob a égide estatal. Duas lideranças especialmente importantes do CEBES durante o processo constituinte foram os médicos Antônio Sérgio Arouca e Eleutério Rodriguez Neto. A mesma função foi exercida pela ABRASCO, criada em 1979, outro importante ator na conformação da política reformista da saúde no contexto da resistência ao regime militar e da transição democrática (COHN, 1989).

Cohn chama corretamente a atenção para a influência da experiência italiana da reforma sanitária, principalmente pela obra de Giovanni Berlinguer, traduzida pelo CEBES para o português em fins da década de 1970. Na obra fundamental Medicina e Política, publicada na Itália em 1973 e no Brasil em 1979, Berlinguer defende a construção institucional de um Serviço Sanitário Nacional com funções integrais de proteção da saúde mitigando o embate anticapitalista endêmico na esquerda italiana na época (BERLINGUER, 1979).

A importante presença do médico e senador do Partido Comunista Italiano demonstrava a forte associação do CEBES à estratégia de ocupação dos espaços institucionais, que foram ampliados pela transição democrática, como lembra Cohn (1989). A orientação para a cooperação institucional, aliada ao aprendizado institucional trazido pela experiência italiana, permitiu ao CEBES apresentar uma proposta extraordinariamente original para a reforma sanitária brasileira. $\mathrm{O}$ documento A Questão Democrática na Área da Saúde, apresentado no I Simpósio sobre Política Nacional de Saúde na Câmara Federal em outubro de 1979 (ESCOREL et al., 2005), foi o principal instrumento da análise política inovadora.

O CEBES propôs os seguintes pontos para a democratização da saúde: 1) o reconhecimento do direito universal à saúde; 2) o reconhecimento do caráter social das condições de saúde: emprego, salário, nutrição, saneamento, habitação e preservação ambiental; 3) a responsabilidade estatal pelo direito à saúde; 4) a criação do Sistema Único de Saúde; 5) o estabelecimento de mecanismos de financiamento, com participação definida da saúde no orçamento da União, estados e municípios; 6) a gestão descentralizada, com articulação federal, estadual e municipal; 7) outorga ao Ministério da Saúde da direção do SUS, com a tarefa de planificar e implantar a Política Nacional de Saúde em cooperação com estados e municípios (FLEURY et al., 2007).

Os elementos anticapitalistas da produção intelectual original foram eliminados ou minimizados em favor do desenvolvimento do setor estatal da 
economia da saúde como escolha estratégica crucial da reforma sanitária. $\mathrm{O}$ documento A Questão Democrática na Area da Saúde propunha, na denominada Política de Assistência Médica,

[...] a suspensão imediata dos convênios e contratos de pagamento por unidades de serviços para a compra de atos médicos ao setor privado empresarial, substituindo-os por subsídios globais; [...] a criação imediata [...] de uma rede regionalizada de ambulatórios e postos de saúde próprios voltados para a aplicação de medidas preventivas articuladas com assistência médica primária, de casos de emergência e de acidentes de trabalho. Para o funcionamento destes postos, deverão ser utilizados médicos funcionários dos Sistemas Únicos; [...] definir uma política de produção e distribuição de medicamentos e equipamentos médicos [...] dirigida à redução da dependência ao capital estrangeiro através da maior participação estatal na pesquisa, formação de pesquisadores e desenvolvimento de tecnologia nacional dirigida à produção de matérias-primas fundamentais à industrialização de medicamentos essenciais [...] (FLEURY et al., 2007, p. 14-15).

A proposta de reforma setorial do CEBES foi também robustecida pelo bem-sucedido experimentalismo na gestão da saúde de governos municipais. No contexto federativo anêmico e restrito, que sobreviveu ao regime militar, as experiências de organização da assistência à saúde nos municípios com governos progressistas foram disseminadas com entusiasmo pelos sanitaristas. Os governos municipais adotaram propostas de ampliação da atenção primária difundidas por canais de interação da comunidade política da saúde pública. Nessa etapa, o desenvolvimento da política municipalista dependeu, sobretudo, das características idiossincráticas dos governos locais e das lideranças progressistas municipais (COSTA et al., 2011). Logo o municipalismo se tornaria um valor fundamental da agenda democratizante dos sanitaristas: a política das Ações Integradas de Saúde (AIS), que perdurou no curto período da transição democrática (1985-1990), reforçou a orientação localista da comunidade política. Em 1986, a proposta o projeto das Açôes Integradas de Saúde (AIS) obteve a adesão de 2.500 municípios (NORONHA; LEVCOVITZ, 1994).

O documento Pelo Direito Universal à Saúde (ABRASCO, 1985) foi uma segunda demonstração da força da análise política dos sanitaristas na transição democrática. O documento ratifica a defesa da "inclusão da saúde no Constituição do Brasil como um dos elementos básicos de afirmação da cidadania do povo brasileiro, situando-a como direito a ser resguardado pelo Estado" (ABRASCO, 1985:7). Segundo a ABRASCO, a reorganização do sistema de saúde brasileiro 
teria como base a universalização e equalização do atendimento à saúde, a descentralização da gestão na gestão dos serviços; a integração institucional entre os vários órgãos e entre os vários níveis de atenção; as novas relações entre os serviços públicos e privados; a definição de uma política de recursos humanos e de ciência e tecnologia; e o desenvolvimento de formas de participação de profissionais e usuários nos serviços de saúde (ABRASCO, 1985).

Falleti (2010) tem razão quando afirma que tanto na VIII Conferência Nacional de Saúde (VIII CNS), realizada em 1986, como durante o processo Constituinte, os sanitaristas já chegaram com uma agenda própria. Cohn \& Elias destacam também que:

[...] When the National Congress elaborated the country's new constitution in 1988, it was the health sector that presented the most complete proposal both in terms of governing principles and in the organization of the system (COHN; ELIAS, 2002, p. 45).

A mesma impressão teve o influente constituinte e médico Carlos Mosconi, do Partido da Mobilização Democrática do Brasil (PMDB) de Minas Gerais, que afirmou:

Tenho recebido várias propostas de todas as áreas. Dentre as propostas que recebi, na área de saúde, talvez a mais abrangente de todas seja [a] da Comissão Nacional d Reforma Sanitária, já uma proposta em termos constitucionais. Peço permissão a Vossa Excelência para ler a proposta que é a seguinte: Art. $1^{\circ}$ A Saúde é um direito assegurado pelo Estado a todos os habitantes do território nacional sem qualquer distinção [...] (MOSCONI, 1987, p. 6).

As recomendações da VIII CNS ratificaram as teses do CEBES e da ABRASCO acerca da saúde de cada indivíduo como sendo de interesse coletivo; o dever do Estado na saúde, a ser contemplado de forma prioritária por parte das políticas sociais; a extensão do direito à saúde e do acesso igualitário às ações e serviços de promoção, proteção e recuperação da saúde em todos os níveis de complexidade (CNRS, 1987). A VIII CNS reiterou a necessidade de mudança no padrão histórico da ação governamental na saúde pela descentralização dos serviços de saúde para os governos subnacionais.

Em relação ao financiamento do novo Sistema Único de Saúde, a VIII CNS propôs a destinação para o setor "de um percentual mínimo sobre as receitas públicas" ou através "de um percentual mínimo de $15 \%$ sobre as receitas públicas" (idem, p. 24). A VIII CNS defendeu um veto aos subsídios diretos aos planos privados de 
assistência à saúde por meio da revisão da dedução do imposto de renda das pessoas físicas e eliminação das deduçôes das empresas com assistência médica (idem).

O documento da VIII CNS, ratificado pelas lideranças políticas democratizantes, defendia a reorganização do Ministério da Saúde como a instância coordenadora do setor; o deslocamento do centro das decisões financeiras para os governos da federação; a democratização decisória pela criação dos Conselhos Deliberativos nos governos da federação com participação de trabalhadores, empregadores, profissionais de saúde e governo; o aumento da participação dos impostos no financiamento da saúde até alcançar o gasto $8 \%$ do PIB em 1990 (BRASIL, 2007).

Alguns dos itens de agenda mais distributivos formulados pela VIII CNS já eram, sem dúvida, amplamente aceitos pelas lideranças políticas vitoriosas pela ascensão da Nova República em 1985. Cabe lembrar que em 1985, já na Nova República (1985-1990), assumiu a presidência do INAMPS um dos mais representativos intelectuais médicos do campo sanitário: Hésio Cordeiro. Nesse ambiente, foi criado por decreto o Sistema Unificado e Descentralizado de Saúde (SUDS), como continuação das Ações Integradas de Saúde, visando fortalecer especialmente o papel dos governos estudais no arranjo federativo do sistema público que se esboçava.

A força mobilizadora da VIII CNS influenciou a criação da Comissão Nacional da Reforma Sanitária (CNRS), de natureza consultiva e com atribuiçōes de formular sugestões para o reordenamento institucional e jurídico do sistema de saúde. A CNRS funcionou de agosto de 1986 a maio de 1987 (CNRS, 1987). Dedicou-se ao aprofundamento do Relatório Final da VIII CNS, à sistematização de propostas e à articulação nacional do movimento sanitário, com atenção para o poder legislativo e o processo constituinte (BRASIL, 2006).

O capítulo da saúde da Constituição Federal de 1988 e as leis e portarias complementares que o seguiram ratificariam, essencialmente, a engenharia organizacional decorrente da proposição da comunidade política dos sanitaristas (ver Anexo A). A Carta de 1988 abriga até os dias atuais a ideia da saúde como direito de acesso universal e igualitário por meio de ações de promoção, proteção e recuperação (Brasil, Constituição Federal, 1988, artigo 196). Do ponto de vista da organização sistêmica, a CF 1988 abrigou a proposta de constituição de um sistema único descentralizado, integral e com participação social (idem, artigo 199). 
Os incentivos institucionais para um processo decisório ampliado e participativo também foram reconhecidos ao se formalizar que o Sistema Único de Saúde contemplaria, em cada esfera de governo, a Conferência e o Conselho de Saúde (BRASIL/MS, 1993). Os Conselhos de Saúde funcionariam de maneira permanente e com caráter deliberativo, sendo compostos pelos governos, prestadores de serviços, profissionais e usuários. Eles atuariam no controle da implantação da política de saúde na instância correspondente e suas decisões seriam "homologadas pelo chefe do Poder Executivo legalmente constituído em cada esfera do governo" (BRASIL/MS, 1993). A legislação que instituiu o Conselho Nacional de Saúde - CNS (Decreto $n^{\circ}$ 99.438/1990) deu-lhe competência para "atuar na formulação da estratégia e no controle da execução da Política Nacional de Saúde”, em nível federal.

\section{Conclusão}

O desenvolvimento do SUS na década de 1990 recebeu avaliações dominantemente pessimistas. Constata-se uma ampla e surpreendente aceitação de que a reforma foi levada adiante em condições precárias e de forma incompleta, desvirtuando a concepção de seus formuladores. Aponta-se de modo geral para a dissociação entre a formulação e a implantação da RS. Nesse terreno, a literatura tem demandado a atenção para a complexa relação entre as esferas públicas e privadas. A constatação de Paim (2008) e Ocké-Reis \& Marmor (2010) é que o SUS imaginado pela comunidade de sanitaristas tornou-se "uma promessa não cumprida”. Ocké-Reis e Marmor afirmam:

[...] the state is incapable of responding to the coverage-related problems caused by budget constraints and this both prevents the SUS from becoming stronger and leaves ample room for the growth of an oligopolistic private health insurance market. (OCKÉ-REIS; MARMOR, 2010, p. 327).

Paim et al. convergem supreendentemente no diagnóstico da promessa não cumprida ao defender que "implementation of the SUS has been complicated by state support for the private sector, the concentration of health services in more developed regions, and chronic underfunding" (PAIM et al., 2011, p. 1.778).

De fato, passados mais de vinte anos da promulgação da CF de 1988, tem se consolidado a configuração fragmentada do sistema de saúde brasileiro. A prevalência do financiamento do seguro privado e do desembolso direto 
das famílias para o custeio da assistência médica impulsiona a fragmentação organizacional do setor. No plano da ação coletiva, a institucionalidade da CF 1988 tem sido apenas a referência cívica para que os indivíduos judicializem o efetivo cumprimento do direito universal acesso à assistência médica e aos medicamentos de alto custo.

Alguns autores têm buscado explicar a dissociação entre a formulação e implantação do SUS pelo legado histórico da organização da assistência médica individual no Brasil. A origem da assistência à saúde, calcada na diferenciação no âmbito dos Institutos de Aposentadoria e Pensão, não favoreceu os valores universalistas da solidariedade na classe trabalhadora brasileira (COHN; ELIAS, 2003; MANICUCCI, 2006).

Outros enfatizam as restrições que a estabilidade monetária e o ajuste fiscal do começo da década de 1990 teriam imposto ao desenvolvimento de uma agenda baseada na ampliação do papel do Estado e dos gastos públicos (PEREIRA, 1996). Nesta abordagem, mesmo o tema da descentralização federativa seria expressão da agenda do Estado mínimo do projeto neoliberal do Executivo federal na década de 1990 (UGÁ, 1997). Nesta perspectiva, Gerschman e Pereira entendem que a RS teria coincidido com a nova era do liberalismo brasileiro quando as políticas sociais ficaram subordinadas à política macroeconômica (GERSCHMAN, 1997; PEREIRA, 1996).

Diniz destaca, com outra visão, que a nova democracia brasileira rompeu com a institucionalidade estatal rígida e de baixo potencial de incorporação política. A nova democracia instaurou um sistema multifacetado de representação de interesses, tornando anacrônico o padrão de Estado onipotente e concentrador (DINIZ, 1997). Ademais, o novo sistema político partidário corroboraria a segmentação na articulação de interesses (VIANNA, 1998).

Manicucci (2006) e Vianna (1998) chamam especial atenção para o papel do movimento sindical que não apoiou a reforma sanitária, mergulhado nas contradiçôes entre a postura ideológica igualitária e a defesa de interesses corporativos. Concomitantemente à implantação da reforma sanitária, a demanda por assistência médica privada transformou-se em item da agenda de negociação coletiva de diversas categorias de trabalhadores, constituindo um "veto implícito" ao modelo público e universal da reforma (VIANNA, 1998; MANICUCCI, 2006). 
Já Faveret e Oliveira (1990) apontam para a hipótese da universalização excludente: a opção, na implantação do SUS, pelo atendimento aos pobres teria produzido o distanciamento da classe média e dos sindicatos do atendimento estatal. As barreiras de acesso derivadas do subfinanciamento governamental visà-vis a massificação do acesso levaram à posição de saída da esfera pública de atores sociais com alto poder de vocalização. A consolidação do mercado de planos privados de assistência à saúde seria decorrência da estratégia de implantação do SUS com base na restrição de oferta de serviços (FAVERET; OLIVEIRA, 1990).

A leitura menos cética sobre o desempenho do SUS está associada à experiência da descentralização. Arretche defende a tese de que a RS foi especialmente bemsucedida na implantação da descentralização federativa. Observa que a autonomia local para a gestão de programas, incentivada pelo Ministério da Saúde, criou oportunidades institucionais para que os governantes implantassem decisões de acordo com suas próprias preferências no âmbito do SUS (ARRETCHE, 2002; 2003). As preferências dos executivos municipais não geraram mal-estar coletivo: os principais avanços nos indicadores de saúde no Brasil seriam atribuíveis ao processo de descentralização (FALLETI, 2010; HUNTER; SUGIYAMA, 2009).

As ciências sociais reconhecem a capacidade da burocracia pública ou elites técnicas em implantar políticas distributivas desenvolvimentistas (EVANS, 1996). As características da política distributiva são muito atraentes: os custos sociais são difusos e os benefícios concentrados em setores e estratos sociais. As decisões desenvolvimentistas distributivas são, assim, recorrentes na história econômica brasileira e renascem vez por outra na cena da área social: não geram veto de nenhum grupo social relevante.

Neste artigo, foi descrita uma experiência extraordinária na história política do país: a conformação da RS, contemplando uma agenda decisória redistributiva. As falhas de implantação lamentadas por parte da literatura nacional são explicáveis porque a agenda redistributiva da RS exigia - e ainda exige- a imposição de perdas concentradas e específicas a setores empresariais e profissionais da saúde. A literatura sobre os modelos institucionais redistributivos é, entretanto, cética sobre a capacidade da burocracia pública ou elites técnicas, isoladamente, levar adiante uma agenda redistributiva sem que seja alcançada uma grande concertação nacional em torno da proposta (ESPING-ANDERSEN, 1996). A análise sobre os limites institucionais para a construção de uma política 
redistributiva na saúde brasileira é, portanto, um grande desafio. Ainda assim, a contribuição da comunidade epistêmica da RS permanece com um legado indispensável para a reconstrução do sistema de saúde brasileiro.

\section{Referências}

ARRETCHE, M. Federalismo e relaçôes intergovernamentais no Brasil: a reforma dos programas sociais. Dados, v.45, n.3, p.431-57, 2002.

. Financiamento federal e gestão local de políticas sociais: o difícil equilíbrio entre regulação, responsabilidade e autonomia. Ciência \& Saúde Coletiva, v.8, n.2, p. 31-345, 2003. Toward a unified and more equitable system: health reform in Brazil. In:

KAUFMAN, R.R.; NELSON, J.M. (Eds.). Crucial needs, weak incentives. Washington, DC: Woodrow Wilson Center Press, 2010. p. $155-188$.

ASSOCIAÇĀO BRASILEIRA PÓS-GRADUAÇÃO EM SAÚDE COLETIVA. Pelo Direito Universal à Saúde. Rio de Janeiro: Comissão de Políticas de Saúde, 1985.

BERLINGUER, G. Medicina e Política. São Paulo: Cebes, 1979.

BRAGA, J.C.; PAULA, S.G. Saúde e Previdência: estudos de política social. São Paulo: Cebes, 1981.

BRASIL. Constituição da República Federativa do Brasil. Brasília: Imprensa Nacional, 1988. . Ministério da Saúde. In: CONFERÊNCIA NACIONAL DE SAÚDE, 8., 17 a 21 de março de 1986. Anais... Brasília: Centro de Documentação do MS, 2007.

- Ministério da Saúde. Descentralização das Ações e Serviços de Saúde. A ousadia de fazer cumprir a Lei. Brasília: Ministério da Saúde, 1993.

. Ministério da Saúde. Primeiro Plano de Desenvolvimento do Setor Saúde. Brasília: Ministério da Saúde, 1985.

Ministério da Saúde. Secretaria de Gestão Estratégica e Participativa. A construção do SUS: histórias da Reforma Sanitária e do Processo Participativo. Brasília: Ministério da Saúde, 2006.

COHN, A.; ELIAS, P.M. Health reform in Brazil: lessons to consider. Am J Public Health, v.93, n.1, p. p. 44-48, 2003.

COHN, A. Caminhos da reforma sanitária Lua Nova, v.19, p. 123-140, 1989.

COMISSÃO NACIONAL DA REFORMA SANITÁRIA. Documentos II. Rio de Janeiro: Secretaria Técnica da Comissão Nacional da Reforma Sanitária, 1987.

CORDEIRO, H.A. A indústria da saúde no Brasil. Rio de Janeiro: Graal, 1980.

COSTA, N. do R. et al. Reforma Psiquiátrica, Federalismo e Descentralização da Saúde Pública no Brasil Ciência e Saúde Coletiva, v.16, n.12, p.4603-4614, 2011. 
COSTA, N. do R. Política e projeto acadêmico: notas sobre a gênese do campo da saúde coletiva. Cadernos de História e Saúde. Rio de Janeiro, n.2, p. 125-136, 1992.

DINIZ, E. Crise, governabilidade e reforma do Estado: em busca de um novo paradigma. In: GERSCHMAN, S.; VIANNA, M.L.T.W. (Eds.). A miragem da modernidade. Democracia e políticas sociais no contexto da globalização. Rio de Janeiro: Fiocruz, 1997. p. 115-_126.

DONNANGELO, M.C.F. Medicina e sociedade. São Paulo: Pioneira, 1975.

DOUBUZINKIS, L.; HOWLETT, M.; LAYCOCK, D. Policy analysis in Canada: the state of the art. Toronto: University of Toronto Press, 2007.

DRAIBE, S.M. Há tendências e tendências: com que Estado de Bem-Estar Social haveremos de conviver? Cadernos de Pesquisa. Campinas, v.10, 1989.

ESCOREL, S.; NASCIMENTO, D.R.; EDLER, F.C. As origens da reforma sanitária e o SUS. In: LIMA, N.T. et al. (Orgs.). Saúde e democracia: história e perspectiva do SUS. Rio de Janeiro: Fiocruz, 2005. p.59-82.

ESPING-ANDERSEN, G. After the Golden Age? Welfare State in a global economy In: (Ed.). Welfare State Transition: national adaptations in global economics. London: Sage, 1996. p. 1-31.

EVANS, P.B.; RAUCH, J. Bureaucracy and growth: a cross-national analysis of the effects of "Weberian" state structures on economic growth. American Sociological Review, v.64, p.748-765, 1999.

FALLETI, T.G. Infiltrating the State. The evolution of health care reforms in Brazil, 19641988. In: MAHONEY, J.; THELEN, K. (Eds.). Explaining institutional change: ambiguity, agency, and power. Cambridge: Cambridge University Press, 2009.

FAVERET, P.; OLIVEIRA, P.J. A universalização excludente reflexões sobre as tendências do sistema de saúde. Planejamento e Políticas Públicas, n.3, p.139-162, jun. 1990.

FLEURY, S.; BAHIA, L.; AMARANTE, P. Saúde em debate: fundamentos da reforma sanitária. Rio de Janeiro: Cebes, 2007.

GERSCHMAN, S. Democracia, políticas sociais e globalização: relações em revisão In: GERSCHMAN, S.; VIANNA, M.L.T.W. (Eds.). A miragem da modernidade. Democracia e políticas sociais no contexto da globalização. Rio de Janeiro: Fiocruz, 1997. p. 155-178.

GRANADOS, F.J.; KNOKE, D. Organized interests groups and political networks. In: JANOSKI, T. et al. (Eds.) The handbook of political sociology: states, civil societies and globalization. Cambridge: Cambridge University Press, 2005. p. 287-309.

HAAS, P.M. Introduction: Epistemic communities and international policy coordination. International Organization, v.46, n.1, p. 1-35, 1992.

HALL, P. The political power of economics ideas: Keynesianism across nations. Princeton: Princeton University Press, 1989. 
HUNTER, W.; SUGIYAMA, N.B. Democracy and social policy in Brazil: advancing basic needs, preserving privilege interests. Latin American Politics and Society, v.51, n.2, p. 29-58, 2009. JAGUARIBE, H. et al. Brasil, 2000: para um novo pacto social. Rio de Janeiro: Paz e Terra, 1986.

KINGDON, J.W. Agenda, alternatives, and public policies. New York: Longman, 2003.

MAJONE, G. Evidence, arguments, and persuasion in the policy process. New Haven: Yale University Press, 1989.

MALLOY, J. Política de Previdência Social no Brasil. Rio de Janeiro: Graal, 1979.

MANICUCCI, T.M.G. Implementação da Reforma Sanitária: a formação de uma política. Saúde e Sociedade, v.15, n.2, p.72-87, 2006.

MOSCONI, C. Atas da Constituinte. Brasília: Senado Federal, 1987.

NORONHA, J.C.; LEVCOVITZ, E. AIS-SUDSSUS: Os caminhos do direito à saúde. In: GUIMARÃES, R.; TAVARES, R. (Eds.). Saúde e Sociedade no Brasil anos 80. Rio de Janeiro: Relume Dumará, 1994. p. 73-112.

NUNES, E. Saúde Coletiva: história de uma ideia e de um conceito. Saúde e Sociedade, v.3, n.2, p.5-21, 1994.

OCKÉ-REIS, C.O.; MARMOR, T.R. The Brazilian National Health System: an unfulfilled promise? International Journal of Health Planning and Management, v.25, p.318-329, 2010.

OLIVEIRA, J.A.; TEIXEIRA, S.M.F. (Im) Previdência social: 60 anos de história da previdência no Brasil. Petrópolis: Vozes, 1985.

PAIM, J.S. A reforma sanitária brasileira e o Sistema Único de Saúde: dialogando com hipóteses concorrentes. Physis: Revista de Saúde Coletiva. Rio de Janeiro, v.18, n.4, p. 625-644, 2008.

PAIM, J.S. et al. The Brazilian health system: history, advances, and challenges. Lancet, v.377, p.1778-97, 2011.

PEREIRA, C. A Política pública como caixa de Pandora: organização de interesses, processo decisório e efeitos perversos na reforma sanitária brasileira (1985-1989). Revista Dados, v.39, n.3, p.423-477, 1996.

SANTOS, W.G. Cidadania e justiça. A política social na ordem brasileira. Rio de Janeiro: Campos, 1979.

UGÁ, M.A. Ajuste estrutural, governabilidade e democracia. In: GERSCHMAN, S.; VIANNA, M.L.T.W. (Eds.). A miragem da modernidade. Democracia e políticas sociais no contexto da globalização. Rio de Janeiro: Fiocruz, 1997. p. 81-100.

VIANNA, M.L.T.W. A americanização perversa da seguridade social no Brasil. Rio de Janeiro: Revan, 1998.

WEYLAND, K. Social movements and the State: the politics of health reform in Brazil. World Development, v.23, n.10, p.1699-1712, 1995. 
ANEXO A

\begin{tabular}{|c|c|c|c|c|c|}
\hline ou Lei & $\begin{array}{l}\text { A Questão } \\
\text { Democrática na } \\
\text { Área da Saúde }\end{array}$ & $8^{\mathrm{a}} \mathrm{CNS}$ & CF - 1988 & Lei $8080 / 90$ & Lei $8142 / 90$ \\
\hline $\begin{array}{l}\text { Conceito } \\
\text { de saúde / } \\
\text { universalização }\end{array}$ & $\begin{array}{l}\text { Direito universal } \\
\text { à saúde. } \\
\text { Reconhecimento } \\
\text { do caráter } \\
\text { socioeconômico } \\
\text { das condições que } \\
\text { viabilizam a saúde }\end{array}$ & $\begin{array}{l}\text { Saúde como direito } \\
\text { de todos e resultante } \\
\text { das formas de } \\
\text { organização social } \\
\text { da produção }\end{array}$ & $\begin{array}{l}\text { Saúde como } \\
\text { direito de todos } \\
\text { e garantida } \\
\text { mediante } \\
\text { políticas sociais e } \\
\text { econômicas que } \\
\text { visem reduzir o } \\
\text { risco de doença e } \\
\text { acesso universal } \\
\text { igualitário às } \\
\text { ações e serviço de } \\
\text { saúde }\end{array}$ & $\begin{array}{l}\text { Direito do ser } \\
\text { humano. Deve } \\
\text { haver acesso } \\
\text { universal e } \\
\text { igualitário às ações } \\
\text { e serviços para a } \\
\text { promoção, proteção } \\
\text { e recuperação da } \\
\text { saúde }\end{array}$ & - \\
\hline $\begin{array}{l}\text { Saúde como dever } \\
\text { do Estado }\end{array}$ & $\begin{array}{l}\text { Saúde como } \\
\text { responsabilidade do } \\
\text { Estado }\end{array}$ & $\begin{array}{l}\text { Saúde como dever } \\
\text { do Estado }\end{array}$ & Dever do Estado & Dever do Estado & - \\
\hline SUS & Criação do SUS & Criação do SUS & Criação do SUS & $\begin{array}{l}\text { Constituição do } \\
\text { SUS }\end{array}$ & - \\
\hline $\begin{array}{l}\text { Participação } \\
\text { democrática / } \\
\text { Conselhos de } \\
\text { Saúde }\end{array}$ & $\begin{array}{l}\text { Participação } \\
\text { democrática da } \\
\text { população nos } \\
\text { diferentes níveis } \\
\text { do sistema e } \\
\text { assembleias e } \\
\text { instâncias próprias } \\
\text { do SUS }\end{array}$ & $\begin{array}{l}\text { Participação popular } \\
\text { na formulaçãoo } \\
\text { de políticas, } \\
\text { planejamento, } \\
\text { gestão, execução e } \\
\text { avaliação das ações } \\
\text { de saúde. Criação } \\
\text { de conselhos nos } \\
\text { diversos níveis }\end{array}$ & $\begin{array}{l}\text { Participação da } \\
\text { comunidade }\end{array}$ & $\begin{array}{l}\text { Veto às instâncias } \\
\text { colegiadas } \\
\text { Conferências de } \\
\text { Saúde e Conselhos } \\
\text { de Saúde }\end{array}$ & $\begin{array}{l}\text { O SUS } \\
\text { contará em } \\
\text { cada esfera de } \\
\text { governo com } \\
\text { Conferências } \\
\text { de Saúde e } \\
\text { Conselhos de } \\
\text { Saúde }\end{array}$ \\
\hline Direção do SUS & $\begin{array}{l}\text { MS dirige o SUS } \\
\text { e INAMPS é } \\
\text { enquadrado neste } \\
\text { sistema }\end{array}$ & $\begin{array}{l}\text { O SUS deve ter um } \\
\text { comando único }\end{array}$ & $\begin{array}{l}\text { O SUS tem } \\
\text { direção única em } \\
\text { cada esfera de } \\
\text { governo }\end{array}$ & $\begin{array}{l}\text { Descentralização } \\
\text { político- } \\
\text { administrativa, } \\
\text { com direção única } \\
\text { em cada esfera de } \\
\text { governo }\end{array}$ & - \\
\hline $\begin{array}{l}\text { Regionalização / } \\
\text { integralidade }\end{array}$ & $\begin{array}{l}\text { Criação de } \\
\text { rede própria } \\
\text { regionalizada }\end{array}$ & $\begin{array}{l}\text { SUS deve ser } \\
\text { regionalizado, } \\
\text { hierarquizado e } \\
\text { propiciar atenção } \\
\text { integral. Progressiva } \\
\text { estatização do setor }\end{array}$ & $\begin{array}{l}\text { Rede } \\
\text { regionalizada e } \\
\text { hierarquizada. } \\
\text { Atendimento } \\
\text { integral, com } \\
\text { prioridade das } \\
\text { açōes preventivas. }\end{array}$ & $\begin{array}{l}\text { Ênfase na } \\
\text { regionalização e } \\
\text { hierarquização da } \\
\text { rede de serviços de } \\
\text { saúde. Realização } \\
\text { integrada das } \\
\text { açôes assistenciais } \\
\text { e das atividades } \\
\text { preventivas }\end{array}$ & - \\
\hline
\end{tabular}




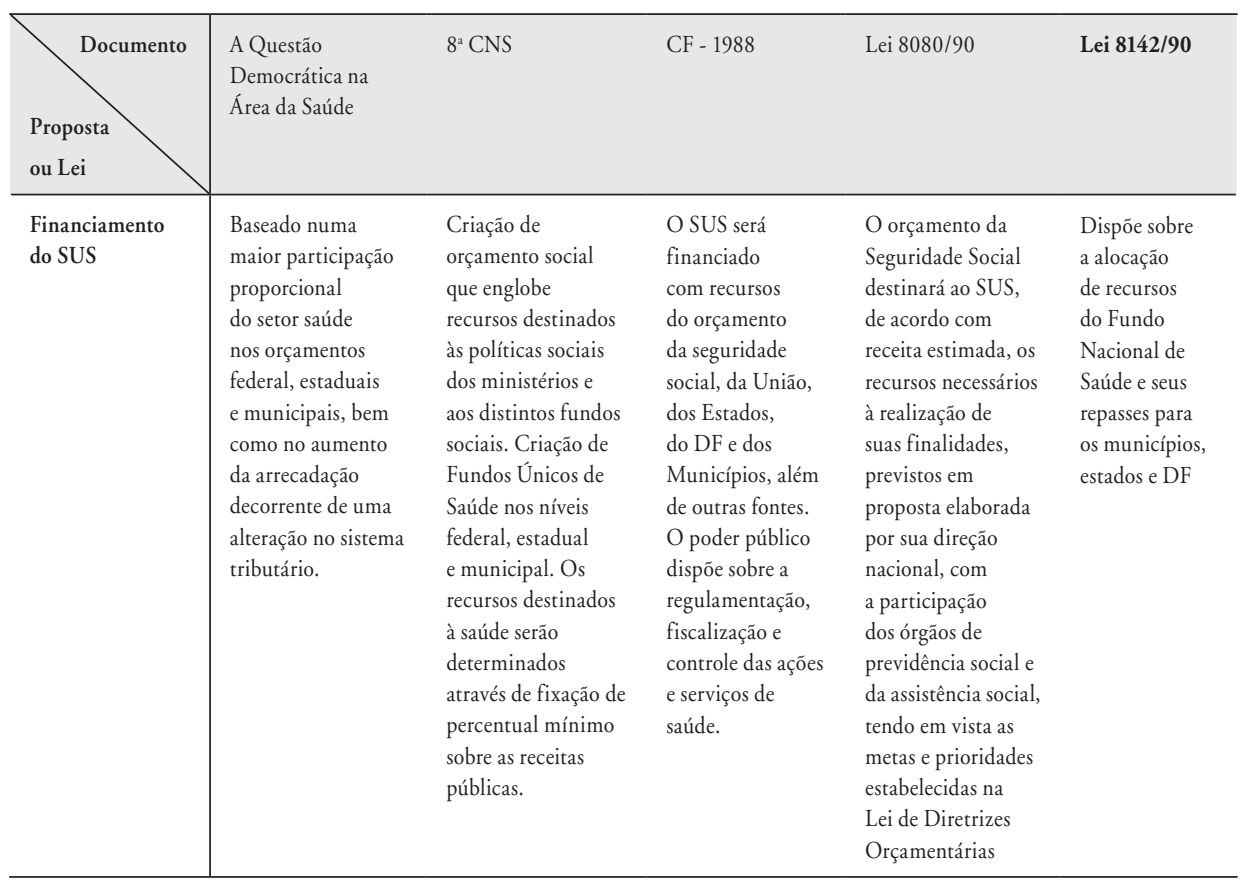




\section{Abstract}

Epistemic community and the formation of health reform in Brazil

This paper addresses the policy analysis that underpinned the Brazilian Sanitary Reform (SR), responsible for the defining the Unified Health System and for the proposal to make universal health care a right under the Federal Constitution of 1988 (FC1988). The paper highlights the role of political argumentation by the epistemic community of experts in the health field as central to the redistributive health sector reform. Although Brazil's health system is defined by the FC1988 as comprising universal access, hegemonic public funding and direct provision of care by the government, today it is fragmented and under huge influence of the private sector. In a comparative perspective, participation by private health insurance is much higher than in other emerging countries. This paper argues that, as FC1988 proposed no veto against the market's operating in the health sector, private health care and health insurance companies with greater voice have succeeded in imposing preferences in decision-making arenas. The paper concludes that the analysis of the institutional limits of redistributive public policies in Brazil presents a challenge to the SR's epistemic community today.

> Key words: health sector reform; epistemic community, new democracy, universalism; privatization. 